\title{
Editorial: Practical pharmacotherapy for anxiety disorders
}

\author{
David Nutt
}

Many authorities consider anxiety to be the psychiatric disorder of the '90s. This is true in terms of the increased recognition of the severity and disabling nature of many anxiety disorders. It is also true from the perspective of the development of new treatments. The past five years have seen a growing recognition of the value of selective serotonin reuptake inhibitors in the treatment of panic disorder, of $5-\mathrm{HT}_{1 \mathrm{~A}}$ agonists such as buspirone in the treatment of generalised anxiety disorder, and the monoamine oxidase inhibitors and reversible inhibitors of monoamine oxidase $A$ in the treatment of social phobia.

This series of three papers, each written by recognised experts, is designed to give a complete overview of the area of pharmacotherapy for the anxiety disorders, extending from basic mechanisms through to practical clinical suggestions. However, it should be emphasised that pharmacological treatments are not the only approaches to anxiety. The growing sophistication of cognitive therapy has led to new approaches to panic, generalised anxiety disorder and obsessive-compulsive disorder, using cognitive-behavioural therapy, and current research is underway to explore the utility of these procedures in both post-traumatic stress disorder and social phobia. Unlike the pharmacological therapies, these approaches have not been evaluated in multi-centre studies. Also, they tend to be less effective in patients with comorbid conditions, particularly depression. However, there is little doubt that in expert hands they are effective alternatives to drug therapy. Drug treatments have the advantage of simplicity and short-term cost. Psychological treatments are more labour-intensive and demand greater involvement of the patient, but may leave the individual with coping strategies which can be applied in future illnesses and therefore may offer improved longerterm outcome. Prevailing opinion would suggest that a combination of drug and psychological treatment is likely to provide additive benefits and would probably be the ideal way to proceed in a fully funded and resourced clinical setting.

\section{Royal College of Psychiatrists and Sainsbury Centre for Mental Health joint venture}

In October 1995 the Royal College of Psychiatrists and the Sainsbury Centre for Mental Health presented a bid to the NHS Executive to hold a joint conference and series of workshops aimed at Consultants and Higher Professional Trainees in Adult Psychiatric Services. This venture has now been awarded a grant and the themes of the workshops will be:

The role of the psychiatrist and the implications for training

The service development skills needed to develop a comprehensive range of mental health services towards the millennium

The agreed 1997 venues are: Telford, 4 March; Norwich, 24 March; Exeter, 29 April; Newcastle upon Tyne, 6 May; Warrington, 16 May; Nottingham, 27 May.

Further details can be obtained from Helen Ashwell of Pavilion Publishing on 01273820120. 